УДК 44.01 .91

\title{
ТЕХНОЛОГИЧЕСКАЯ СХЕМА ПЕРЕРАБОТКИ ЗОЛОШЛАКОВЫХ ОТХОДОВ ДЛЯ ПОВЫШЕНИЯ ЭКОЛОГИЧНОСТИ ГЕНЕРАЦИИ ЭНЕРГИИ НА МАГАДАНСКОЙ ТЭЦ
}

\author{
Гайдай Наталия Константиновна \\ к.Г.-М.Н., доценТ \\ Кузьменков Максим Андреевич \\ Шипунов Лев Викторович \\ ФГБОУ ВО «Северо-Восточный \\ государственный университет»
}

Аннотация: В статье рассматривается экологичность генерации электроэнергии как приоритетная задача научно-технологического развития Российской Федерации. Отсутствие в Магаданской области полигонов твердых коммунальных отходов, в полной мере отвечающих требованиям экологической безопасности, делает актуальными исследования по разработке технологий для безотходного производства. Технологическая схема переработки золошлаковых отходов Магаданской ТЭЦ позволит осуществить обогащение золы с целью извлечения полезных элементов.

Ключевые слова: золоотвал, Магаданская ТЭЦ, золошлаковые отходы, экологичность, лаборатория обогащения, СВГУ.

\section{TECHNOLOGICAL SCHEME OF ASH WASTE PROCESSING TO INCREASE ENERGY GENERATION ENVIRONMENTALITY AT THE MAGADAN CHPP}

\section{Gayday Natalia Konstantinovna Kuzmenkov Maxim Andreevich Shipunov Lev Viktorovich}

\begin{abstract}
Environmental friendliness of electricity generation is among the priority tasks of the scientific and technological development of the Russian Federation. The absence in the Magadan Region of solid municipal waste landfills
\end{abstract}


that fully meet the requirements of environmental safety makes research on the development of technologies for waste-free production urgent. The technological scheme for the processing of ash and slag waste from the Magadan CHPP will allow for the enrichment of ash in order to extract useful elements.

Key words: ash dump, Magadan CHPP, ash and slag waste, environmental friendliness, enrichment laboratory, NESU.

Основной отраслью экономики Магаданской области была и остается горнодобывающая промышленность. Энергетика, обеспечивающая существование и развитие горнодобывающей отрасли, отнесена ко второй по значимости и объемам производства [1].

Тепловые электростанции на территории Магаданской области выполняют функции производства как электрической, так и тепловой энергии (преимущественно ПАО Магаданэнерго, ПАО Колымаэнерго, а также другие предприятия, имеющими котельные).

По состоянию на 2020 год в число тепловых электростанций магаданской энергосистемы входят: Аркагалинская ГРЭС с установленной электрической мощностью 224 МВт (при этом в настоящее время в выработке элетроэнергии участвует оборудование мощностью $47 \mathrm{MBT}$ ) и Магаданская ТЭЦ (МТЭЦ) с установленной электрической мощностью 75 МВт (с ДЭС - 96 МВт) [1].

Магаданская ТЭЦ выполняет важную социальную функцию обеспечение энергией населения города Магадана. Это - основная задача ее работы. Попутно станцией вырабатывается и электроэнергия. Станция представляет собой паротурбинную теплоэлектроцентраль, где в летнее время работают только электрокотлы. В остальное время генерация энергии на станции происходит путем сжигания ископаемого топлива - угля. Продолжительность отопительного периода в Магадане составляет 278 суток [2].

В семидесятые годы прошлого столетия для использования в качестве топлива на Магаданской ТЭЦ рассматривался уголь, добываемый на Аляске. Было осуществлено его пробное сжигание на действующем тогда оборудовании. Эксперимент показал, что для эффективного использования этого угля требовалась только реконструкция систем пылеприготовления, расходы по которой компании США готовы были взять на себя. Однако, проблемным оказалась транспортировка аляскинского угля в порт г. Магадана. 
Экономически выгодной она могла быть только при грузоподъемности судов от 100 тысяч тонн, прием которых не мог осуществлять магаданский морской порт [3].

Оборудование Магаданской ТЭЦ проектировалось для использования ургальских и аркагалинских углей [4]. Но высокая степень летучести этих углей приводила к взрывам пылесистем. Аварийные ситуации сопровождались вырыванием столпов пламени из раскрытых клапанов на циклонах.

Наиболее эффективным для работы на оборудовании Магаданской ТЭЦ оказалось топливо из Кузнецкого угольного бассейна. Сегодня здесь работают с энергетическим углем марки Д и ДГ Талдинского угольного разреза [5].

Сегодня актуальным является вопрос о рациональном природопользовании. Любое производство должно обеспечивать экологическую безопасность. Золошлаковые отходы работы ТЭС содержат в себе практически всю таблицу Менделеева, однако, как правило, им присваивается четвертый класс опасности [6, 7]. Наибольший вред приносит распыление мелких фракций. Проблемой является именно накопление золошлаковых отходов и их складирование.

Идею использования золы еще в прошлом веке предложил американский профессор P.Е. Дэвис, однако активно этот вопрос начал рассматриваться только в 90-е годы. Зарубежные страны сегодня эффективно используют технологии промышленной переработки отходов горения угля. В немалой степени этому способствовали новые стандарты, регулирующие выбросы в угольной промышленности, в частности - Международная конвенция по защите растений (International Plant Protection Convention, IPPC), Директива Евросоюза о крупных установках по сжиганию топлива (Large Combustion Plants Directive, LCPD), Директива по промышленным выбросам (Industrial Emissions Directive, IED). Переработку продуктов горения угля отслеживают Европейская ассоциация по утилизации продуктов горения угля (Coal Combustion Products) и Азиатская ассоциация угольной золы (Asian Coal Association).

В России перерабатывается лишь малый процент золошлаковых отходов - в основном их добавляют в цементы, иногда используют для отсыпки дорог. В подавляющем количестве случаев отечественные исследования по использованию золошлаковых отходов не доходят до промышленной стадии. В результате в регионах, где энергия производится тепловыми электрическими 
станциями, использующими уголь, количество складированных на полигонах отходов ежегодно растет.

Магаданская ТЭЦ располагает двумя основными площадками для хранения продуктов горения угля [8]. Одна из них уже заполнена, законсервирована и рекультивирована. Вторая площадка заполнена практически на 70\%. При нынешних темпах сжигания угля ее заполнение ожидается до конца 2023 г.

Для Магаданской области, где отсутствуют полигины твердых коммунальных отходов, отвечающие действующим требованиям экологической безопасности и требованиям санитарных правил и норм, вопрос переработки отходов производства стоит очень остро [1, 9]. Вопрос о комплексном использовании золоотвалов в дальнейшем производстве с целью минимизации его воздействия на окружающую среду становится в ряд приоритетных задач, поставленных стратегией научно-технологического развития Российской Федерации [10].

Ранее были разработаны проекты по добавлению золы в бетоны для использования их в массовом строительстве новых микрорайонов в г. Магадане (ссылка). Также предлагалось добавление золы в другие строительные материалы, изготавливающиеся на местном рынке для мелкого жилищного строительства. Но широкого распространения предложенные технологии не получили.

Представляемая работа преследует целью экспериментальное изучение вопроса возможности энергоэффективного обогащения золы Магаданской ТЭЦ для создания условий безотходного производства. В качестве основного ценного компонента извлечения на данном этапе рассматривается диоксид титана. Область его применения сегодня -химическая, фармацевтическая, строительная, радиоэлектронная и другие отрасли производства.

Анализ имеющейся по данному вопросу информации показал наличие возможности обогащения титана и его рационального извлечения. Для подтверждения практической целесообразности данного процесса был проведен геохимический лабораторный анализ золы пережженного угля с подземного рудника, уголь которого по генезису имеет схожий с используемым на Магаданской ТЭЦ состав.

Полученные в результате анализа данные стали основой для разработки комплексных обогатительных схем, которые построены путем объединения 
уже известных технологических схем обогащения титаново-циркониевых россыпей традиционного аллювиального типа. Построенная технологическая цепочка обеспечивается энергоэффективным оборудование обогащения лаборатории полезных ископаемых политехнического института СевероВосточного государственного университета (г. Магадан) - винтовыми и магнитными сепараторами, шлюзами глубокого наполнения и др. (рис.1). Предварительная оценка разработанной технологической схемы обогащения позволяет рассчитывать на технологическую и экономическую эффективность принятых решений.

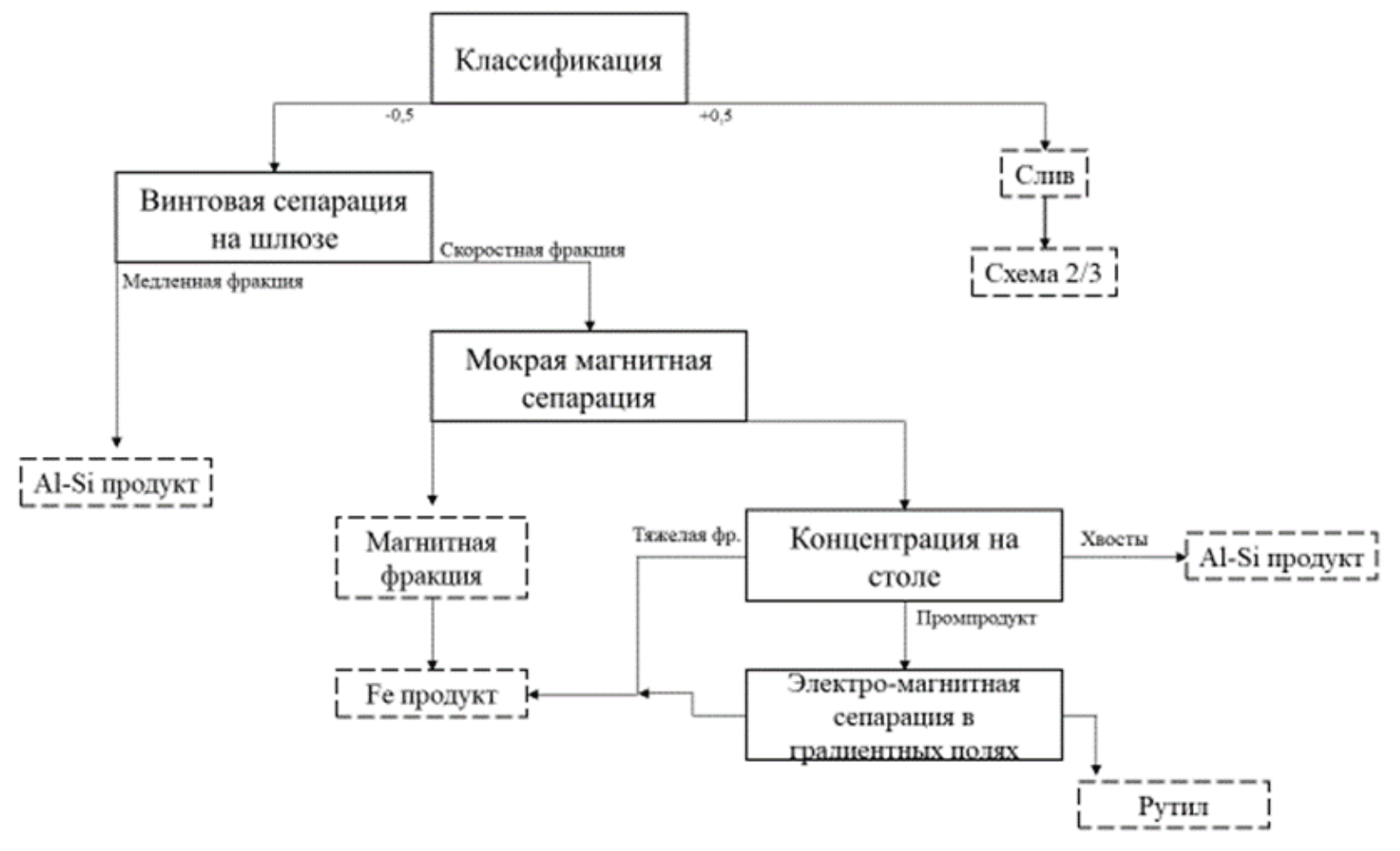

\section{Рис.1. Основная технологическая схема обогащения золы МТЭЦ в лаборатории}

Представленная технологическая схема разработана для угля, прошедшего первичную подготовку к сжиганию в виде предварительного измельчения до 0,2 мм, а также грохочение от металлических и деревянных включений. Для крупных частиц, встречающихся в золошлаках, разработана вспомогательная схема дообогащения.

Достоинством разработанной технологической схемы является не только ее реализация в виде стационарного комплекса в лаборатории обогащения СВГУ, но и возможность реализации в виде модульной установки, которая может быть перемещена на площадку золоотвала. 


\section{Список литературы}

1. Стратегия социально-экономического развития Магаданской области на период до 2030 года // Электронный фонд правовых и нормативнотехнических документов. [Электронный pecypc]. URL: https://docs.cntd.ru/document/561763699. Дата обращения 29.10.2021.

2. СП 131.13330.2020. Строительная климатология. [Электронный pecypc]. URL: http://sniprf.ru/sp131-13330-2018. Дата обращения 16.10.2021.

3. Магаданская ТЭЦ: на краю страны //Magadanmedia [Электронный pecypc]. URL: https://magadanmedia.ru/news/656295/. Дата обращения 26.11.2021.

4. Схема теплоснабжения муниципального образования «город Магадан», Проект Постановления Мэрии г. Магадана. С.-Петербург, 2021. [Электронный ресурс]. URL: https://magadan.49gov.ru/common/download/. Дата обращения 19.11.2021.

5. Магаданэнерго завезет более 300 тысяч тонн угля для отопительного сезона 2021-2022 // Сайт ПАО «Магаданэнерго» Батакова О.Г (2021). URL: http://www.magadanenergo.ru/content/magadanenergo-zavezet-bolee300-tysyach-tonn-uglya-dlya-otopitelnogo-sezona-2021-2022. дата обращения 03.05.2021.

6. З Зола, образующаяся на наших ТЭС, не содержит ядов. Энергетика // Экология // Индустрия / [Электронный ресурс]. URL: https://kislorod.life/opinions/zola_obrazuyushchayasya_na_nashikh_tes_ne_soderzhit _yadov/ Дата обращения 20.11.2021.

7. Золошлаковые отходы // Инжиниринговый химикотехнологический центр. Химические технологии. [Электронный ресурс]. URL: https://ect-center.com/. Дата обращения 20.11.2021.

8. Сведения о поднадзорных Федеральной службе по экологическому, технологическому и атомному надзору гидротехнических сооружениях, подлежащих декларированию безопасности в 2021 году [Электронный ресурс]. URL: https://www.gosnadzor.ru/energy/safety/ declarirovanie_bezopasnosti_gts. Дата обращения 15.11.2021.

9. СанПиН 2.1. 7 .1038-01«Гигиенические требования к устройству и содержанию полигонов для твердых бытовых отходов». [Электронный ресурс]. URL: https://docs.cntd.ru/document/901789953. Дата обращения 07.04.2020. 
10. Стратегия научно-технологического развития Российской Федерации. [Электронный ресурc]. URL: https://нтр.pф/challenges-priorities/ Дата обращения 04.05.2021.

(С) Н.К. Гайдай, М.А. Кузьменков, Л.В. Шипунов, 2021 